\title{
口FEATURE
}

\section{Hypertension in the ED}

Martin D. Klinkhammer, MD, MPH

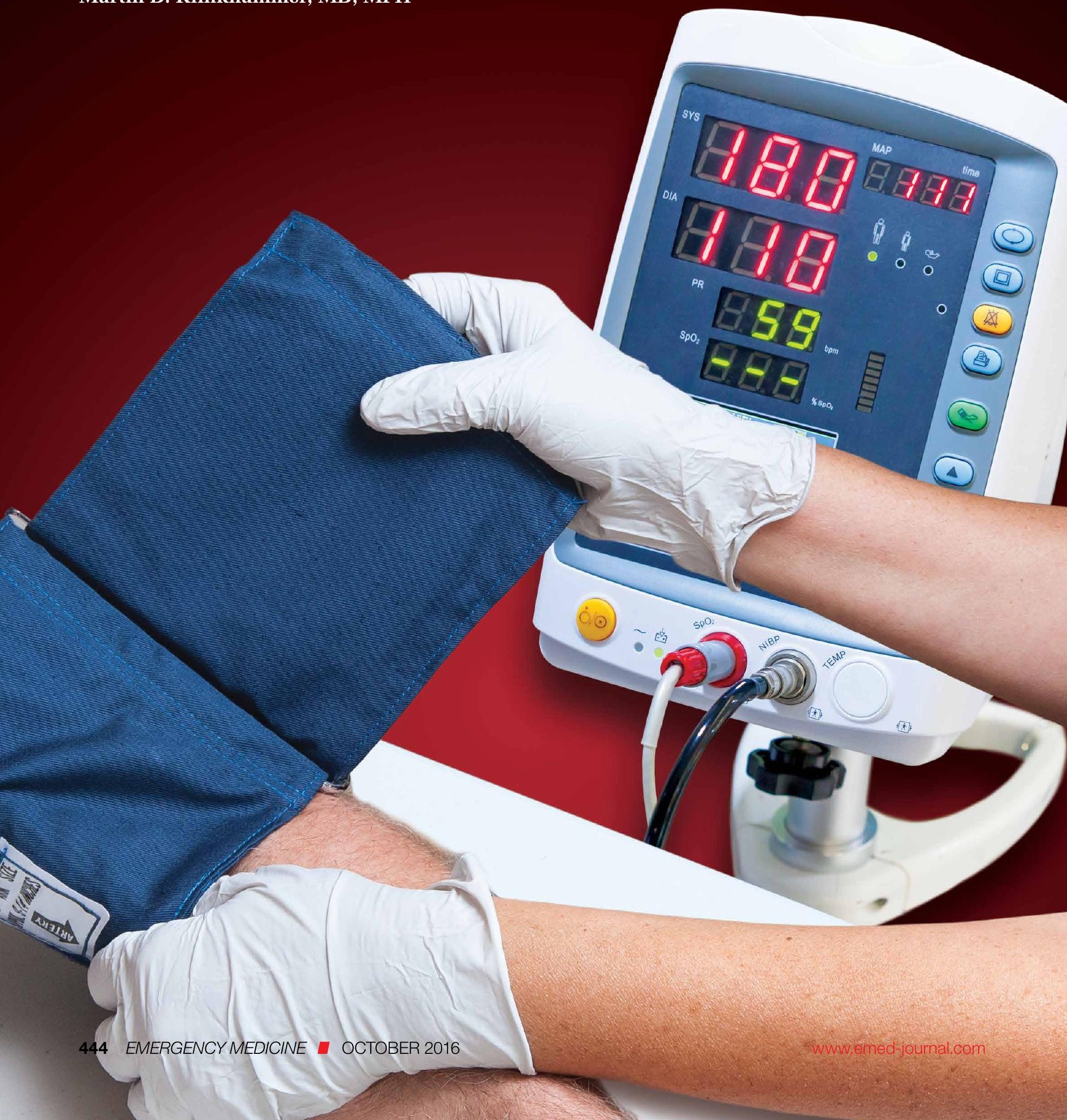




\section{Most ED patients with hypertension will present either without symptoms or with only mild headache. This review covers the most up-to-date guidelines for treating these patients.}

\section{Case Scenarios}

\section{Case 1}

You had just started your shift, and your first patient presented with symptoms of headache and dizziness, and a blood pressure (BP) of 240/130 mm Hg, without any vomiting or visual symptoms. Physical examination revealed an alert, pleasant 65-year-old black man whose ocular, neurological, and cardiovascular (CV) examinations were normal. The patient reported a history of borderline hypertension, but had never taken any medications for it.

After placing some initial orders, including an electrocardiogram (ECG), basic metabolic panel (BMP), and head computed tomography (CT) scan, and ordering $10 \mathrm{mg}$ intravenous (IV) prochlorperazine and 25 mg IV diphenhydramine to treat the patient's headache, you are left asking yourself what steps you should take next.

\section{Case 2}

Your next patient was a 90-year-old white woman who had been referred to the ED by her primary care physician (PCP) for "hypertensive urgency." She had no complaints to report. Similar to the first patient, this patient's physical examination was also normal, with the exception of a persistently elevated BP of 220/140 mm Hg. Her history was significant for congestive heart failure (CHF), but she exhibited no current CV signs or symptoms. The patient had been taking furosemide but was not on any other antihypertensive medications.

\section{Case 3}

In the room next to your 90-year-old patient is a 32-year-old uninsured hypertensive white woman. During the history taking, the patient stated that she was trying to become pregnant and was not currently using any form of contraception. Similar to the second patient, she had no complaints to report. Regarding her reason for presentation, the patient stated that when she had her BP checked at a pharmacy earlier that day, the reading was "too high," and the pharmacist had advised her to go to the ED. She seemed anxious but otherwise well. Her initial BP at presentation was 240/100 $\mathrm{mm} \mathrm{Hg}$, but her physical examination was otherwise normal.

\section{Hypertensive Emergencies}

As emergency physicians (EPs), we see hypertensive patients every day. According to the US Centers for Disease Control and Prevention, 33\% of American adults have hypertension, which is defined by a BP of 140/90 mm Hg (Table 1). Hypertension remains uncontrolled in over $50 \%$ of these patients ${ }^{1}$ and contributes to a large disease burden, including stroke, CV disease, and kidney failure. Treatment of hypertension has been proven effective in reducing morbidity and mortality. ${ }^{2}$

Almost $25 \%$ of total annual US adult ED visits are directly or indirectly related to hypertension, and about $1 \%$ of all ED visits are due solely to elevated $\mathrm{BP}^{3}$ In an ambulatory care survey for 2007, moderate

Dr Klinkhammer is an assistant professor, department of emergency medicine, Eastern Virginia Medical School, Norfolk; and an emergency physician, Emergency Physicians of Tidewater, Norfolk, Virginia.

Author's Disclosure Statement: The author reports no actual or potential conflict of interest in relation to this article.

DOI: 10.12788/emed.2016.0062 
Table 1. Definition and Classification of Ambulatory Blood Pressure in Adults ${ }^{15,17}$

\begin{tabular}{lcc}
\hline Category & $\begin{array}{c}\text { Systolic } \\
\mathbf{( m m ~ H g )}\end{array}$ & $\begin{array}{c}\text { Diastolic } \\
(\mathbf{m m ~ H g})\end{array}$ \\
\hline Optimal & $<120$ & $<80$ \\
\hline High normal & $120-139$ & $80-89$ \\
\hline Grade 1 hypertension & $140-159$ & $90-99$ \\
\hline Grade 2 hypertension & $160-179$ & $100-109$ \\
\hline Grade 3 (severe) hypertension & $\geq 180$ & $\geq 110$ \\
\hline
\end{tabular}

or severe hypertensive BP readings were found to be more common in patients presenting to the ED (43.5\%) than to primary care clinics $(27 \%) .{ }^{4}$ Patients presenting to the ED with hypertensive $\mathrm{BP}$ readings disproportionately represented patients who were older, male, non-Hispanic black, Medicare beneficiaries, or uninsured. Certainly, some patients presenting to the ED have hypertensive BP readings due to pain or anxiety, but multiple studies have suggested that $50 \%$ to $70 \%$ of ED patients who have hypertensive BP readings will be diagnosed with hypertension on office follow-up. ${ }^{5,6}$ While a minority of these patients present to the ED with hypertensive emergencies, the majority present either without symptoms of hypertension or with only mild headache. Given the disease burden of hypertension combined with the benefits of treatment, it is worthwhile for the practicing EP to review the most up-todate guidelines on outpatient management of hypertension.

When a patient presents to the ED with a hypertensive BP reading, the initial priority of the EP is to exclude hypertensive emergency. Hypertensive emergencies are defined by the presence of hypertension (generally grade 3/severe hypertension with $\mathrm{BP} \geq 180 / 110 \mathrm{~mm} \mathrm{Hg}$; see Table 1) in conjunction with evidence of target organ damage. The organs that manifest the complications of severe hypertension and their associated hypertensive emergencies are listed in Table 2. The organs affected include the heart and vascular system, eyes, brain, and kidneys.

\section{Target Organ Manifestations}

The acuity and/or presence of target organ damage are not always clear on initial ED evaluation. For instance, when a patient who has no history of primary care presents to the ED with severe hypertension, laboratory evaluation may demonstrate protein and blood in his or her urine and an elevated serum creatinine level. In the absence of values from past laboratory studies, it is difficult to determine whether these test results represent normal laboratory parameters for this patient due to longstanding hypertensive kidney disease (ie, hypertensive nephrosclerosis) or if they represent a true hypertensive emergency, (ie, hypertensive emergency-related nephropathy). ${ }^{7}$ In patients with severe hypertension and possibly new acute kidney injury, it is probably safest to either assume hypertensive emergency-related nephropathy and to treat accordingly or consult with nephrology services. The picture of hypertensive emergency-related nephropathy often only becomes clear after renal biopsy results and improvement in renal parameters with BP control.

The ocular manifestations of hypertensive emergency require detailed fundoscopy, which at times can be challenging in the ED. In assessing for cardiac target organ damage, at our institution, we typically ask patients if they have experienced symptoms of dyspnea and chest pain or pressure. Generally, we also evaluate cardiac enzymes, B-type natriuretic peptide, and order ECG and chest X-ray studies when suggested by history or physical examination. Alarmingly, a study of 161 ED hypertensive (average BP of 183/109 mm Hg), asymptomatic, predominantly black patients found that 146 (90.7\%) had subclinical hy- 
pertensive heart disease on point-of-care echocardiogram. ${ }^{8}$

\section{Neurological/Hypertensive Encephalopathy} Hypertensive encephalopathy is a diagnosis of exclusion as alternate causes of confusion and headache, such as intracranial hemorrhage, are excluded and mental status improves with titrated BP control. Nonetheless, it is difficult to confidently state from the literature that patients who present with headache but have a normal mental status in the presence of severe hypertension are not on an early spectrum of hypertensive encephalopathy. Therefore, it is likely that the degree of symptoms should define whether target organ damage exists, though there is certainly a spectrum of hypertensive emergency-the strict definition of which is not always clear.
When a hypertensive emergency is diagnosed, management typically involves the use of antihypertensive IV medication in the intensive care unit. While such management is outside the scope of this paper, Adebayo and Rogers ${ }^{9}$ have published an excellent review of the care of hypertensive emergencies.

\section{Asymptomatic Hypertension}

The American College of Emergency Physicians (ACEP) has developed two clinical policies on the evaluation and management of asymptomatic hypertension in the ED. The original, published in 2006, advised that initially high BP readings of ED patients should be repeated: two separate high readings are adequate for screening, and those patients with hypertension should be referred for follow-up. Further-

Table 2. Organ Damage Reflecting Hypertensive Emergencies ${ }^{9}$

\begin{tabular}{|c|c|c|}
\hline $\begin{array}{l}\text { Organ Systems Affected } \\
\text { by Hypertensive Emergency }\end{array}$ & $\begin{array}{l}\text { Disease State(s) Caused } \\
\text { by Severe Hypertension }\end{array}$ & $\begin{array}{l}\text { Physical/Laboratory/ } \\
\text { Radiographic Evaluation }\end{array}$ \\
\hline Ocular system & $\begin{array}{l}\text { Hypertensive retinopathy } \\
\text { (papilledema, flame hemorrhages) }\end{array}$ & Fundoscopy \\
\hline \multirow[t]{4}{*}{ Cardiovascular system } & Pulmonary edema & Electrocardiogram \\
\hline & Myocardial ischemia & Chest X-ray imaging \\
\hline & Aortic dissection & Cardiac enzymes \\
\hline & & $\begin{array}{l}\text { Computed tomography angiography } \\
\text { of the chest/abdomen }\end{array}$ \\
\hline \multirow[t]{4}{*}{ Central nervous system } & Hypertensive encephalopathy & Noncontrast head computed tomography \\
\hline & Cardiovascular accident & Magnetic resonance imaging \\
\hline & $\begin{array}{l}\text { Posterior reversible encephalopathy } \\
\text { syndrome }\end{array}$ & \\
\hline & Hypertensive intracranial hemorrhage & \\
\hline \multirow[t]{6}{*}{ Renal system } & Acute renal failure & Urinalysis \\
\hline & Hypertensive emergency & Basic metabolic panel \\
\hline & Renal disease & Complete blood count \\
\hline & Microangiopathic hemolytic anemia & Lactate dehydrogenase \\
\hline & & Haptoglobin \\
\hline & & Indirect bilirubin \\
\hline
\end{tabular}


If treatment for hypertension is initiated in the ED, such management should attempt only to gradually lower $\mathrm{BP}$, and not to normalize it during the initial ED visit. more, ACEP policies note that initiating treatment in the ED is not necessary when patients are referred for follow-up. If treatment for hypertension is initiated in the ED, ACEP recommends that such management should attempt only to gradually lower BP, and not to normalize it during the initial ED visit. ${ }^{10}$

The 2013 update to ACEP's clinical policy on managing asymptomatic hypertension expanded on the original policy. The updated policy advised against routine testing for target organ damage in patients who have asymptomatic severe hypertension. However, ACEP policy notes that evaluating serum creatinine in these patients with poor follow-up may influence patient disposition. ${ }^{11}$

The 2013 policy further stated that medical intervention is not required in ED patients who have asymptomatic severe hypertension, but may be considered in patients with poor follow-up. The policies emphasize that all asymptomatic hypertensive patients should be referred for followup. The literature cited for the recommendation that ED patients with asymptomatic severe hypertension do not require routine investigation stems from two observational studies. These studies found that screening asymptomatic ED patients who presented with severe hypertension revealed serum creatinine abnormalities in approximately $6 \%$, which impacted patient disposition, though it was not clear from the study results whether admission correlated to meaningful patient outcomes. ${ }^{12,13}$

\section{Patient Disposition}

Since ACEP's 2013 clinical policy, a study from the Cleveland Clinic has been published. This retrospective cohort study reviewed 6 years of data looking at all patients in its system with a BP of $\geq 180 / 110$ $\mathrm{mm} \mathrm{Hg}$, and compared those office patients discharged to home to those referred to the ED or directly admitted to the inpatient hospital solely on the basis of severe hypertension. ${ }^{14}$ The study found that $0.5 \%$ of 387 patients referred to the ED by primary care clinics for asymptomatic severe hypertension had confirmed acute kidney injury on BMP. ${ }^{14}$ The Cleveland Clinic study also found that $2.1 \%$ of patients had evidence of target organ damage and 5.5\% had any abnormal results. ${ }^{14}$ In addition, referral to the ED from the clinic for hypertension was associated with a slightly higher rate of major adverse CV events at 7 days (2 of 426 [0.5\%] versus 61 of 58,109 [0.1\%]; $P=.02) .{ }^{14}$

The results of the Cleveland Clinic study confirm that in the absence of target organ damage, hypertension is probably best managed in the outpatient setting. The European Task Force hypertensive guidelines state "hospitalization for hypertension is regarded as inappropriate in most European countries." ${ }^{15}$ However, from 2006 to 2012, 26\% of US ED patients with primary diagnoses of hypertension were admitted to the hospital. ${ }^{3}$ In Canada's most populous province of Ontario, from 2002 to 2011 , approximately $8 \%$ of hypertensive patients were admitted. ${ }^{16}$ Part of this discrepancy may be due to the sometimes ambiguous nature of the presentation of patients with hypertension, making it unclear whether a true hypertensive emergency exists. Many patients perceive visual symptoms, headache, dizziness, and even chest pressure as the result of their elevated $\mathrm{BP}$-without clear findings on fundoscopy, ECG, or cardiac marker testing. Perhaps more of these patients would be discharged if EPs felt comfortable initiating appropriate initial antihypertensive treatment.

\section{Management}

\section{Initiating Antihypertensive Treatment}

Some EPs may feel that an accurate diagnosis of hypertension requires repeat $\mathrm{BP}$ testing in the primary care office setting, and for this reason are reluctant to initiate antihypertensive treatment in the ED. The most recent guidelines by the Joint National Committee (JNC 8) do not address 
how many BP readings are necessary to diagnose hypertension, but JNC 7 suggested that diagnosis of hypertension requires two separate office visits. ${ }^{17}$ Evidence cited in ACEP's first clinical policy states that two separate BP measurements in the ED are adequate for screening-but not necessarily for initiating treatment. ${ }^{10}$ However, European and British outpatient clinical recommendations advocate initiation of antihypertensive medication for a single visit in patients who have an elevated $\mathrm{BP}$ categorized as grade $3 /$ severe hypertension (BP of $\geq 180 / 110 \mathrm{~mm} \mathrm{Hg}$ ). ${ }^{15,18}$ Furthermore, for patients with severe hypertension seen in the $\mathrm{ED}$, as many as $97 \%$ are likely to have true hypertension at office followup. ${ }^{6}$ Those ED patients presenting with severe hypertension are very likely to have a true diagnosis of hypertension.

A recent retrospective analysis of a group of hypertensive ED patients by Brody et $\mathrm{al}^{19}$ found that patients prescribed BP medications by an EP were more likely to have improved BP control at follow-up 2 weeks later. In their study, the decision to prescribe antihypertensive medications were at the discretion of the EP. Seventy-six patients were given one or more prescriptions for antihypertensive therapy, compared to a control group of 141 patients who were not given a prescription. On follow-up at 2 weeks, there was an $11 \mathrm{~mm} \mathrm{Hg}$ greater reduction of BP in the group who received prescriptions compared to the control group. None of the patients in either group on follow-up had experienced any new neurological deficits, ischemic events, life-threatening anaphylactic reactions, or clinically significant hypotension.

The Cleveland Clinic study ${ }^{14}$ also reported on those patents given who received new prescriptions from the ED. Similar to the study by Brody et al, ${ }^{19}$ none of the 82 patients discharged to home from the ED with a new antihypertensive prescription had any major adverse event at 30-day follow-up. ${ }^{14}$

\section{Pharmacological Treatment Recommendations}

When choosing to treat patients with new prescriptions for antihypertensives, it is important to follow the most current outpatient treatment recommendations. In 2014, JNC 8 released new guidelines for the outpatient management of adults with hypertension. ${ }^{20}$ The panel issued recommendations based on its systematic review of randomized controlled trials on antihypertensive treatments. The key recommendations are as follows:

- In patients aged 60 years or older, initiate pharmacological treatment at a $\mathrm{BP}$ of $\geq 150 / 90 \mathrm{~mm} \mathrm{Hg}$.

- In patients aged 18 to 59 years, initiate pharmacological treatment at a BP of $\geq 140 / 90 \mathrm{~mm} \mathrm{Hg}$.

- In the general nonblack population, initial antihypertensive treatment should include a thiazide-type diuretic, a calcium channel blocker (CCB), an angiotensinconverting enzyme inhibitor (ACE-I), or an angiotensin receptor blocker (ARB).

- In the general black population, initial treatment should include a thiazide-type diuretic or a CCB.

- In patients with chronic kidney disease (CKD) (including black patients), initial (or add-on) antihypertensive treatment should include an ACE-I or ARB to improve kidney outcomes-but not both.

च If goal BP is not reached within 1 month of initial treatment, increase the dose of the initial drug or add a second agent (eg, thiazide-type diuretic, CCB, ACE-I, or ARB). If goal is not reached with two drugs, use the third drug from that list if no contraindications exist, but do not use both an ACE-I and an ARB together in the same patient.

Of note, JNC 8, in departure from JNC 7 , no longer recommends beta-blockers as first-line therapy for isolated hypertension (there may be compelling alternate indications, such as atrial fibrillation or postmyocardial infarction (MI), such that a betablocker would still be the first medication 
considered). The reason for this stems from a single randomized controlled trial of 9,193 patients that found that despite equivalent $\mathrm{BP}$ reduction, use of a betablocker in comparison to an ARB resulted in a higher rate of a composite outcome of death, MI, or stroke. ${ }^{21}$ The main difference was a $25 \%$ relative risk reduction for stroke with use of an ARB (losartan) in comparison to a beta-blocker (atenolol). The most recent European guidelines still include beta-blockers among its first-line recommended BP medications, but do acknowledge that they are not as effective in reducing stroke incidence as other alternative medications. ${ }^{15}$ The European guidelines otherwise include the same list of first-line agents. The British guidelines mirror JNC 8 in terms of first-line antihypertensive medication choices. ${ }^{18}$

Since the release of JNC 8, the Systolic Blood Pressure Intervention Trial (SPRINT) has been published, and will likely impact future national recommendations on
BP management. The SPRINT study was a randomized controlled trial enrolling over 9,000 hypertensive nondiabetic patients older than age 50 years that treated individuals to a standard BP goal (systolic $\mathrm{BP}$ of $140 \mathrm{~mm} \mathrm{Hg}$ ) versus an intensive BP goal (systolic BP of $120 \mathrm{~mm} \mathrm{Hg}$ ) over a 3.5year period. The trial was stopped early for safety as a $25 \%$ mortality reduction was observed in the intensive treatment group (1.65 vs 2.19 deaths/y). ${ }^{22}$ This was in contrast to previous trials that had mostly failed to show this sort of benefit, though previous trials were smaller in number or included only diabetic patients. ${ }^{23}$ While it is likely that this trial may influence lowering treatment thresholds from the office, it is not likely to impact care from the ED.

The recommendations of JNC 8 do not necessarily coincide with current US EP practice. In the study by Brody et $\mathrm{al},{ }^{19}$ of patients provided ED antihypertensive prescriptions, $54 \%$ received thiazide-type diuretics, 26\% ACE-I, 10\% CCBs, and 6\%

Table 3. Compelling and Possible Contraindications to the Use of Antihypertensive Drugs ${ }^{13}$

\begin{tabular}{lll}
\hline Drug & Compelling Contraindication(s) & Possible Contraindication(s) \\
\hline Thiazide-type diuretics & Gout & $\begin{array}{l}\text { Metabolic syndrome } \\
\text { Hypokalemia } \\
\text { Glucose intolerance } \\
\text { Pregnancy } \\
\text { Hypercalcemia }\end{array}$ \\
& & Heart failure \\
\hline $\begin{array}{l}\text { Calcium channel blockers } \\
\text { (dihydropyridines) }\end{array}$ & Tachyarrhythmia \\
\hline $\begin{array}{l}\text { Angiotensin-converting } \\
\text { enzyme inhibitors }\end{array}$ & Pregnancy & Women with child-bearing potential \\
& Hyperkalemia & \\
& Angioedema & \\
\hline Angiotension receptor blockers & Bilateral renal artery stenosis & Pregnancy \\
& Hyperkalemia & Women with child-bearing potential \\
& Bilateral renal artery stenosis & \\
& &
\end{tabular}


beta-blockers. This is noteworthy because $96 \%$ of those in the study were black patients who would benefit most from either a thiazide or a CCB. Another recent study of ED patients showed that of patients who were both treated in the ED and discharged with antihypertensive medications, 34\% received a diuretic prescription, $32 \%$ clonidine, $15 \%$ a beta-blocker, $19 \%$ an ARB or ACE-I, $12 \%$ a CCB, and $2 \%$ hydrazine. $^{24}$ These results are important because according to many published guidelines, including JNC 8, clonidine is only considered one of several fourth-line options for severe resistant hypertension. ${ }^{15,18,20}$ Since clonidine use can be complicated by rebound hypertension, it is not an ideal agent to be prescribed de novo to patients in the ED. This is particularly true if these patients are not already on maximum doses of the three most recommended agents previously noted, or if there are concerns over patient compliance.

Of the drug classes recommended by JNC 8, Table 3 lists the absolute and relative contraindications. Of note, potential side effects associated with thiazide diuretics are hypokalemia and hyponatremia. The ARB or ACE-I antihypertensives can worsen or induce hyperkalemia. For this reason, patients typically started on a thiazide should have periodic evaluation of sodium and potassium levels. ${ }^{15,17,25}$ Patients who have renal disease or who are at risk for renovascular disease should have repeat BMP evaluation 1 to 2 weeks after starting an ARB or ACE-I. ${ }^{26}$ Therefore, while ACEP may advise baseline testing of hypertensive patients is unnecessary, if choosing to start an ACE-I, ARB, or thiazide diuretic, a BMP should probably be checked. Oftentimes this will need to be repeated in the primary care office 1 to 2 weeks later. This may complicate choosing any of these agents from the ED.

In clinical trials, amlodipine is among the most effective BP medications and is considered first-line therapy for all groups of patients with hypertension. ${ }^{15,18,20} \mathrm{~A}$ sim- plistic approach for most patients presenting with severe asymptomatic hypertension (BP of $\geq 180 / 110 \mathrm{~mm} \mathrm{Hg}$ ) not currently on treatment would be to recheck the $\mathrm{BP}$ and assure it remains elevated over the period of the ED visit. If it does, refer for followup, and consider prescribing amlodipine on ED discharge. In patients with baseline CKD or with history of CHF, consider alternatively starting them on an ARB or ACE-I. If starting an ARB or ACE-I, a baseline BMP should probably be checked and patients at risk for renovascular disease should be advised they require follow-up for repeat BMP in 1 to 2 weeks. Table 4 lists the commonly prescribed antihypertensive medications and typical dose ranges.

\section{Conclusion}

Hypertension is among the most common medical conditions for which emergency patients seek care. The ACEP clinical policies provide guidance on the appropriate work-up and treatment of these patients. Given the occasional lack of clarity on whether a patient's presentation is on the spectrum of more acute/serious, EPs may feel more comfortable in discharging patients with poor follow-up if they are able to safely prescribe antihypertensive treatment. Prior to prescribing treatment, EPs should refer to the JNC 8 guidelines to appropriately start antihypertensive treatment in select patient groups in the ED. The guidelines of JNC 8 are therefore worth referring to in order to appropriately start treatment in select patient groups from the ED.

\section{Case Scenarios Continued Case 1}

[The 65-year-old black man who presented with headache and dizziness, and had an initial BP of 240/130 mm Hg.]

After treating the patient with prochlorperazine and diphenhydramine, his headache resolved. His BP improved but remained elevated at 190/120 mm Hg. On further questioning, the patient reported a 
Table 4. First-line Treatment Options for the Outpatient Treatment of Hypertension ${ }^{20}$

\begin{tabular}{|c|c|c|}
\hline Drug & Dose Range & Average Price/1-Month Supply \\
\hline $\begin{array}{l}\text { Calcium channel blockers } \\
\text { (dihydropyridine) }\end{array}$ & $5-10 \mathrm{mg} / \mathrm{d}$ & $\begin{array}{l}\$ 4.00 \\
\text { (Average cost on many retailer prescription lists) }\end{array}$ \\
\hline \multicolumn{3}{|l|}{-Amlodipine } \\
\hline Thiazide-type diuretics & & $\$ 4.00$ \\
\hline -Chlorthalidone & $12.5-25 \mathrm{mg} / \mathrm{d}$ & (Average cost on many retailer prescription lists) \\
\hline -Hydrochlorothiazide & $12.5-50 \mathrm{mg} / \mathrm{d}$ & \\
\hline $\begin{array}{l}\text { Angiotensin-converting } \\
\text { enzyme inhibitors }\end{array}$ & & $\begin{array}{l}\$ 4.00 \\
\text { (Average cost on many retailer prescription lists) }\end{array}$ \\
\hline -Benazepril & $20-40 \mathrm{mg} / \mathrm{d}$ & \\
\hline -Captopril & 25-50 mg twice daily dosing & \\
\hline -Lisinopril & $10-40 \mathrm{mg} / \mathrm{d}$ & \\
\hline \multicolumn{3}{|c|}{ Angiotensin receptor blockers } \\
\hline -Irbesartan & $150-300 \mathrm{mg} / \mathrm{d}$ & $\sim \$ 10.00$ \\
\hline -Losartan & $80-320 \mathrm{mg} / \mathrm{d}$ & $\sim 25.00$ (dose-dependent) \\
\hline -Valsartan & $50-100 \mathrm{mg} / \mathrm{d}$ & $\sim \$ 15.00$ \\
\hline
\end{tabular}

history of similar headaches and wondered whether it was related to his BP. The head CT scan was negative for any acute hemorrhage, infarct, or mass; the ECG only showed evidence of left ventricular hypertrophy; and the BMP showed normal renal function.

After a long discussion with the patient, you agreed to start him on amlodipine 5 $\mathrm{mg} / \mathrm{d}$ and referred him for follow-up with a local PCP.

\section{Case 2}

[The 90-year-old white woman with a history of $C H F$ and an initial $B P$ of 220/140 $\mathrm{mm} \mathrm{Hg}$ at presentation.]

The BMP evaluation showed a baseline creatinine level of $1.3 \mathrm{mg} / \mathrm{dL}$. Given this patient's history of CHF, amlodipine would not be the ideal next agent to prescribe. After discussion with her PCP, you elected to start her on losartan at $25 \mathrm{mg} / \mathrm{d}$, and instructed her to follow-up with her PCP within 1 week.

\section{Case 3}

[The 32-year-old white woman who presented at the advice of a pharmacist and had an initial BP of 240/100 $\mathrm{mm} \mathrm{Hg}$.]

While reviewing the patient's work-up and history, you noted her plans to become pregnant, and recalled a recent review on BP management, noting the contraindications associated with ARB or ACE-I in pregnancy. Based on the patient's uninsured status and poor follow-up, you considered prescribing amlodipine. Prior to issuing the prescription, you performed a repeat BP check and noted that the patient's BP had decreased to 130/85 mm Hg. Given the marked improvement in the patient's BP during her ED course, you were not convinced that she truly had hypertension.

Instead of prescribing an antihypertensive agent, which may not ultimately benefit this patient, you advised her to seek follow-up care at an outpatient clinic to have her BP rechecked. The patient agreed, and you referred her to a local free clinic. 


\section{References}

1. Nwankwo T, Yoon SS, Burt V, Gu Q. Hypertension among adults in the United States: National Health and Nutrition Examination Survey, 2011-2012. NCHS Data Brief. 2013;(133):1-8.

2. Turnbull F; Blood Pressure Lowering Treatment Trialists' Collaboration. Effects of different bloodpressure-lowering regimens on major cardiovascular events: results of prospectively-designed overviews of randomised trials. Lancet. 2013;362(9395):15271535.

3. McNaughton CD, Self WH, Zhu Y, Janke AT, Storrow $\mathrm{AB}$, Levy P. Incidence of hypertension-related emergency department visits in the United States, 2006 to 2012. Am J Cardiol. 2015;116(11):1717-1723. doi: 10.1016/j.amjcard.2015.09.007.

4. Niska RW. Blood pressure measurements at emergency department visits by adults: United States, 2007-2008. NCHS Data Brief. 2011;(72):1-8.

5. Chernow SM, Iserson KV, Criss E. Use of the emergency department for hypertension screening: a prospective study. Ann Emerg Med. 1987;16(2):180-182.

6. Backer HD, Decker L, Ackerson L. Reproducibility of increased blood pressure during an emergency department or urgent care visit. Ann Emerg Med. 2003.41(4):507-512.

7. Nonaka K, Ubara Y, Sumida K, et al. Clinical and pathological evaluation of hypertensive emergencyrelated nephropathy. Intern Med. 2013;52(1):45-53.

8. Levy P, Ye H, Compton S, et al. Subclinical hypertensive heart disease in black patients with elevated blood pressure in an inner-city emergency department. Ann Emerg Med. 2012;60(4):467-474.e1. doi: 10.1016/j.annemergmed.2012.03.030.

9. Adebayo O, Rogers RL. Hypertensive emergencies in the emergency department. Emerg Med Clin North Am. 2015;33(3):539-551. doi: 10.1016/j. emc.2015.04.005

10. Decker WW, Godwin SA, Hess EP, Lenamond CC, Jagoda AS; American College of Emergency Physicians Clinical Policies Subcommittee (Writing Committee) on Asymptomatic Hypertension in the ED. Clinical policy: critical issues in the evaluation and management of adult patients with asymptomatic hypertension in the emergency department Ann Emerg Med. 2006;47(3):237-234. doi: 10.1016/j. annemergmed.2005.10.003

11. Wolf SJ, Lo B, Shih RD, Smith MD, Fesmire FM; American College of Emergency Physicians Clinical Policies Committee. Clinical policy: critical issues in the evaluation and management of adult patients in the emergency department with asymptomatic elevated blood pressure. Ann Emerg Med. 2013;62(1):59-68. doi: 10.1016/j.annemergmed.2013.05.012.

12. Karras DJ, Kruus LK, Cienki JJ, et al. Evaluation and treatment of patients with severely elevated blood pressure in academic emergency departments: a multicenter study. Ann Emerg Med. 2006;47(3): 230-236.

13. Nishijima DK, Paladino L, Sinert R. Routine testing in patients with asymptomatic elevated blood pressure in the ED. Am J Emerg Med. 2010;28(2):235-242. doi: 10.1016/j.ajem.2008.11.015.

14. Patel KK, Young L, Howell EH, et al. Characteristics and outcomes of patients presenting with hypertensive urgency in the office setting. JAMA Intern Med. 2016;176(7):981-988. doi: 10.1001/jamain- ternmed.2016.1509.

15. Mancia G, Fagard R, Narkiewicz K, et al. 2013 ESH/ ESC guidelines for the management of arterial hypertension: the Task Force for the Management of Arterial Hypertension of the European Society of Hypertension (ESH) and of the European Society of Cardiology (ESC). Eur Heart J. 2013;34(28):21592219. doi: 10.1093/eurheartj/eht151.

16. Masood S, Austin PC, Atzema CL. A populationbased analysis of outcomes in patients with a primary diagnosis of hypertension in the emergency department. Ann Emerg Med. 2016;68(3):258-267.e5. doi: 10.1016/j.annemergmed.2016.04.060.

17. Chobanian AV, Bakris GL, Black HR, et al; National Heart, Lung, and Blood Institute Joint National Committee on Prevention, Detection, Evaluation, and Treatment of High Blood Pressure; National High Blood Pressure Education Program Coordinating Committee. The Seventh Report of the Joint National Committee on Prevention, Detection, Evaluation, and Treatment of High Blood Pressure: the JNC 7 report. $J A M A$. 2003;289(19):2560-2572. Erratum in: JAMA. 2003;290(2):197.

18. Krause T, Lovibond K, Caulfield M, McCormack T, Williams B; Guideline Development Group. Management of hypertension: summary of NICE guidance. BMJ. 2011;343:d4891. doi: 10.1136/bmj.d4891.

19. Brody A, Rahman T, Reed B, et al. Safety and efficacy of antihypertensive prescription at emergency department discharge. Acad Emerg Med. 2015;22(5):632-635. doi: 10.1111/acem.12660.

20. James PA, Oparil S, Carter BL, et al. 2014 evidencebased guideline for the management of high blood pressure in adults: report from the panel members appointed to the Eighth Joint National Committee (JNC 8). JAMA. 2014;311(5):507-520. doi: 10.1001/jama.2013.284427. Erratum in: JAMA. 2014;311(17):1809.

21. Dahlöf B, Devereux RB, Kjeldsen SE, et al; LIFE Study Group. Cardiovascular morbidity and mortality in the Losartan Intervention For Endpoint reduction in hypertension study (LIFE): a randomised trial against atenolol. Lancet. 2002;359(9311):995-1003.

22. PRINT Research Group, Wright JT Jr, Williamson JD, Whelton PK, et al. A randomized trial of intensive versus standard blood-pressure control. $N$ Engl J Med. 2015;373(22):2103-2116. doi: 10.1056/NEJMoa1511939.

23. ACCORD Study Group, Cushman WC, Evans GW, Byington RP, et al. Effects of intensive bloodpressure control in type 2 diabetes mellitus. $N$ Engl JMed. 2010;362(17):1575-1585. doi: 10.1056/NEJMoa1001286.

24. Levy PD, Mahn JJ, Miller J, et al. Blood pressure treatment and outcomes in hypertensive patients without acute target organ damage: a retrospective cohort. Am J Emerg Med. 2015;33(9):1219-1224. doi: 10.1016/j.ajem.2015.05.036.

25. Leung AA, Wright A, Pazo V, Karson A, Bates DW. Risk of thiazide-induced hyponatremia in patients with hypertension. Am J Med. 2011;124(11):10641072. doi: 10.1016/j.amjmed.2011.06.031.

26. Mann JFE, Hilgers KF. Renin-angiotensin system inhibition in the treatment of hypertension. http:// www.uptodate.com/contents/renin-angiotensinsystem-inhibition-in-the-treatment-of-hypertension. Accessed September 21, 2016. 